\title{
Corporate Social Responsibility and Human Resource Management in different countries
}

\author{
Ginevra Gravili \\ Department of Economics \\ University of Salento \\ Lecce, 73100, Italy
}

\begin{abstract}
The presence of Corporate Social Responsibility (CSR) in firms has grown in recent years but the rate of adoption among nations diverges considerably. The way to involve employees and the diffusion of the socially responsible values into the organizational culture can depend to the cultural dimensions of a country. This paper explores the relationship between attitudes to Corporate Social Responsibility (CSR) and the cultural dimensions of business activity identified by Hofstede (2005) and Globe (2004) through a longitudinal analysis of Cranet Network based on 2,678 firms located in 13 countries. This paper attempts to focus on the relationship between environmental sustainability in terms of CRS and culture, interpreting the HRM practices in "green organization". This study can be used as a guide for managers, giving an indication of the link between environmental strategy, human resource management and culture dimensions across countries.
\end{abstract}

Keywords: Sustainability, HRM, CSR, Cultural dimensions.

\section{Introduction}

The diffusion of Corporate Social Responsibility (CSR) (Caroll, 1999) in the last decade has contributed to the development of a rising interest in linking sustainability to Human Resource issues (Ehnert, 2009). Organizations have begun to recognize potential strategic value in pursuing CSR policies (McWilliams and Siegel, 2006) and that sustainability is not only a simple application of rules but also one that incorporates a social dimension. In this context, a new green economy is born, in which the capacity of developing new Human Resource Management (HRM) models is able to create a sustainable work place where there is cohesion and the differences between people may represent an asset to be used to benefit the organizations and the very same people. The tangible and intangible benefits associated with for organization are immense. The presence of CSR in HRM, implementing knowledge sharing, can be a way to integrate environmental practices into an organization. The idea is that the knowledge sharing can help the manager to transform a simple application of environmental rules in knowledge for the organization.
The ability to build "green worker" develops "environmental knowledge" that becomes a core competence, a factor that affects the performances and the acquisition of competitive advantages, a factor in which a company learns how to change. CSR became one of the important ways in which an organization can achieve competitive advantage, distinguishing itself from its competitors. It can be useful not only for profit, but also for the brand image and reputation and for " the war for talent". In fact, the use of green practice could help managers to retain employees and attract new candidates. In its true sense, CSR is a way of thinking which permeates all organizational culture involving all resources in responsible behaviors. It is obvious that top management, in general, and Human Resource Management Department, in particular, have to encourage sustainable processes. In this process, an important role can have cultural dimensions. This is fundamental if we consider that many managers view environmental management as compliance: a lot of environmental regulations, trade-offs between environmental and economic performance (Walley, 1994). In this study, our goal is to highlight if top managers in different cultural contexts choose to apply sustainable strategies, analyzing them in terms of using CSR values in HRM in 13 countries, gathered through the CRANET research.

\section{Definitions}

The terms "sustainability", "sustainable development", "corporate sustainability" and "corporate social responsibility" are used interchangeably by many. Sustainability "is the ability to meet the needs of the present without compromising the ability of future generations to meet their own needs" (WCED, 1987). It refers to all aspects of social life and environmental impacts.

Sustainable development is indeed "a process of achieving human development. In an inclusive manner, connected, equitable, prudent and safe" (Gladwin et al., 1995).

In 1997 Elkington introduced triple bottom line to explain to firms the concept of sustainability. It is performance measurement of an organization pursuing a sustainable 
strategy. "A company sustainable, then, is one that contributes to sustainable development by offering simultaneously economic, social, environmental". It's central to understanding sustainability (Savitz and Weber, 2006).

The CSR is "the sum of the voluntary actions taken by a company to address the economic, social and environmental impacts of its business operations" (JonesChristensen, 2007).

At a corporate level, sustainability is the focus on creating of a business model that is sustainable from an ecological, financial and social point of view. It identifies "strategies and practices that contribute to a more sustainable world, create value for shareholders and for the company, at the same time.

CSR, however, is responsible for decreasing the negative impacts of corporate actions in the pursuit of a business strategy and, therefore, it is considered largely voluntary and is often practiced at the tactical level without affecting the core business process.

In this paper we use CSR and Sustainability as a synonym for Sustainable Development.

\section{Conceptual model - National Culture and Sustainability}

"There are differences in the way that people who identify with different cultures, based on both national identity and gender, manage their communicative behaviors" (Rosen et. al, 2010). For this reason, in the last decade, numerous researches (Katz, Swansons and Nelson, 2001) have focused on the relationship between environmental sustainability and culture even if there are few studies in the literature on the influence of national culture on CSR strategies and practice, compared to the financial-social performance debate or the investigation of firm- and industry-level factors explaining CSR engagement. Cultural dimensions that characterize nations are identified, today, as critical factors for the CSR of companies and in particular for multinational corporations (Gravili, Miglietta and De Leo, 2016; Srnka, 2004), so much so that Visser (2008) stresses the need for more comparative works investigating national differences in CSR implementation. There are different results in this research area.

In this respect, Ringov and Zollo (2007) have linked Hofstede's cultural dimension to CSR and they have demonstrated that there is a negative correlation between power distance and CSR, that is, in countries with high levels of power distance there is a low social and institutional capacity for environmental sustainability. The same result was found for the dimension of masculinity, which evidentially has a similar effect. Ringov and Zollo have, however, not find proof of a significant influence regarding the dimensions of uncertainty avoidance and collectivism.

Another research of Halkos and Skouloudis (2016) demonstrated that three of the Hofstede's six cultural dimensions affect CSR penetration. Specifically, elements of long-term versus short-term orientation and indulgence versus restraint affect positively the composite CSR index while uncertainty avoidance has a negative effect. In contrast, the effect of, individualism, power distance and masculinity is found to be insignificant.

The literature review suggests that there are different approaches towards research attempts to investigate country-specific CSR and conduct cross-cultural comparisons. Some studies addressed differences of CSR between countries by focusing on the situation in Europe (Silberhorn and Warren, 2007) or between Europe and the U.S. (Maignan and Ralston, 2002). In turn, some crosscultural or cross-national studies indicated that the differences in the cultural and social backgrounds result in different views on CSR in different culture-specific contexts. Following this perspective, some investigatory comparisons were made among Asian countries (Chapple and Moon, 2005) and among countries in Europe, Asia, North America and other regions (Baughn et al, 2007). With respect to countries of northern Europe, the previous research indicates that there is more CSR activity in Northern than in Southern Europe with the most philanthropic companies were found in Norway (Welford, 2004, 2005).

In order to discover the impact cultural dimensions have on sustainability, we examined the bivariate correlation between sustainability and cultural dimensions. On the basis of literature review, the research proposes two multiple regression models for statistical testing. In particular, Hofstede's and Globe's cultural dimensions are, separately, uncorrelated with the presence or absence of CSR statement. Our model analyses the sustainability of 2,678 firms of 13 countries.

We hypotheses that:

Hypothesis 1. Hofstede or Globe's cultural dimensions influence sustainability.

Hypothesis 2. The relation between CSR and Hofstede or Globe's cultural dimensions is positive/negative and relevant.

\section{Empirical analysis}

From the theoretical discussion, which introduced sustainability importance in HRM processes, the correlations among cultural dimensions and sustainability are analysed, to identify appropriated models in different cultural environments.

\section{Dependent Variable}


The dependent variable is CSR. We use the results of Cranet survey and in particular the presence or absence of CSR statement in firms. Cranet is a network of scholars from universities across the world, representing over 40 countries. Cranet conducts a survey of HRM in member countries approximately every four years, enquiring into policies and practices in people management through a set of common questions. In this research, we look at dimensions of societal culture, using data from Austria, Brazil, Denmark, Finland, Greece, Israel, Italy, Philippines, Russia, South Africa, Spain, Sweden, USA that have participated Hofstede (Table n. 1), Globe (Table n. 2) and Cranet's studies.

\section{Independent variables Cultural Variables}

Cultural Variables

Our model aims to analyze environmental sustainability and Hofstede and House's culture model. Hofstede's model analyses 7 dimensions:

1. Power Distance (PDI) expresses the degree to which the less powerful members of a society accept and expect that power is distributed unequally.

2. Individualism (IDV) measures the degree of how much people are integrated into groups. That means is there a feeling of "we" or "I".

3. Masculinity (MAS) expresses the society`s preference for achievement, heroism, success on the masculine side - or the preference for cooperation, taking care for others and quality of life on the feminine side.

4. Uncertainty Avoidance (UAI) expresses how people, in different countries, deal with uncertainty and ambiguity.

5. Pragmatic (PRA) examines the society's thinking on the present and the future. Long-term oriented societies try to live in a sustainable way - they try to change the circumstances to get a maybe even better future. Whereas short-term oriented societies foster virtues related to the past and present such as national pride, respect for tradition, preservation of "face", and fulfilling social obligations. The Pragmatic dimension was included in 2010 Michael Minkov's survey based on research. This dimension deals with recent values. The results are delivered by the World Values Survey. The Long Term Orientation and the Pragmatic vs Normative dimension are dealing with similar questions and as a matter of fact the outcome of the survey is very similar but not identical. The Hofstede Centre uses the Pragmatic vs Normative approach for its surveys.
The Pragmatic vs Normative dimension describes the desire of people to explain the things, which are going on all around us. In normative societies, people want to explain everything and want to explore the secret how something is happening. Whereas in pragmatic societies people just try to deal with the circumstances and live their way without thinking how things are going on. They are more likely to accept and adapt to different circumstances.

6. Indulgence (IND) is the sixth dimension that was also added in 2010. In a society with a high level of indulgence it is very easy to gratify the natural human drives and basic needs and desires as well as to have fun. In restraint countries the society tries to control every part of human life and restricts the gratification of the mentioned needs by rules and norms.

Table 1 Hofstede's cultural dimensions of analysed countries

\begin{tabular}{|c|c|c|c|c|c|c|c|c|c|c|c|c|c|}
\hline & . Smrific & \begin{tabular}{|l|l|} 
Breuzii \\
\end{tabular} & Dentratr & 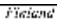 & Ginve: & jowatei & Sisting & 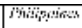 & jürsizar & Sisth dy tit in & Sprein & \begin{tabular}{|l|} 
Si. siefe \\
\end{tabular} & EST \\
\hline$P^{2 D i}$ & 35 & $6 \%$ & 71 & 63 & $3:$ & 13 & 76 & 91 & 34 & .15 & 37 & 71 & 19 \\
\hline iiin & 11 & 33 & 15 & 13 & s0 & 51 & 50 & 32 & 5,3 & 65 & 31 & 31 & 91 \\
\hline WHAS & 74 & 19 & 16 & 2 th & 57 & .17 & 70 & 61 & 36 & 63 & 12 & 5 & \$2 2 \\
\hline LAAi & 73 & 76 & $2 !$ & 34 & 112 & 81 & 75 & .11 & 55 & 14 & sh & 29 & 16 \\
\hline Pill & 63 & 11 & 70 & 37 & 50 & $3 \%$ & 30 & 27 & 70 & 31 & 1: & 78 & 24 \\
\hline 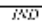 & कil & 5y & $2 !$ & $7 !$ & 1! & $\pi$ & 61 & 12 & 81 & 63 & 111 & $5 !$ & $6 ! 5$ \\
\hline
\end{tabular}

House's model consider nine Cultural dimensions:

1. Assertiveness (ASS) measures how confrontational and aggressive individuals behave in contact with others.

Collectivism is constituted by two indicators, which measure the:

2. Institutional collectivism (IC) on the one hand. It indicates "the degree to which organizational and societal institutional practices encourage and reward collective distribution of resources and collective action" (House et al., 2004)

3. In-group collectivism (INC) on the other hand. It is "the degree to which individuals express pride, loyalty, and cohesiveness in their organizations or families" (House et al, 2004)

4. Future Orientation (FO). It is "the degree to which a collectivity encourages and rewards future-oriented behaviors such as planning and delaying gratification" (House et al, 2004.

5. Gender egalitarianism (GE). Gender egalitarianism is "the degree to which a collective minimizes gender inequality" (House et al, 2004)

6. Power Distance (PD). Characteristics of societies that have high and low power distance (House et al, 2004)

7. Humane Orientation (HO). It is "the degree to which an organization or society encourages and 
rewards individuals for being fair, altruistic, friendly, generous, caring, and kind to others" (House et al, 2004)

8. Performance Orientation (PO). It reflects the extent to which a community encourages and rewards innovation, high standards, excellence, and performance improvement (Grove, 2005).

9. Uncertainty Avoidance (UA). It is "the extent to which a society, organization, or group relies on social norms, rules, and procedures to alleviate the unpredictability of future events" (House et al., 2004)

In Globe's study each dimensions has two indexes, practices or "as is," and values or "should be."

In our analysis we consider only practice index.

Table 2 Globe's cultural dimensions of analysed countries

\begin{tabular}{|c|c|c|c|c|c|c|c|c|c|c|c|c|c|}
\hline & rasritia & Brazit & ivenfiatr: & म̈нїы & C & jorket & Fitaly & 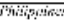 & ikurstia & 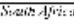 & Sirzaia & Sit. stien & C.S.1 \\
\hline ASS & 4,55 & 1.2 & $4 . \infty$ & 4,05 & 4.55 & 4,19 & 4,12 & 1,111 & 3,85 & 1,36 & 1.12 & 3,41 & 4.5 \\
\hline$i$ & 4,34 & 3.13 & 4.53 & 4,77 & 3.41 & 4.4 & 1,75 & 1,95 & $<.57$ & 1,39 & $3 . x 5$ & 5.25 & 4,21 \\
\hline$\overline{W C}$ & 4,85 & 5.16 & 3,63 & $4,2]$ & 5.28 & 4,53 & 4,39 & 6.35 & 5,83 & 5,119 & 5.15 & 3.45 & 4,22 \\
\hline Wivi & $4, \angle 7$ & 3.81 & 4.59 & 4,35 & 3.53 & 1,12 & 1,34 & $1,1:$ & 3,05 & 1,51 & 3.51 & 4.177 & $4,1]$ \\
\hline Kit. & 3,15 & 3.11 & 4.02 & 3,55 & 3.53 & 1,21 & 3.1 & 3.31 & 4,07 & 3 , sib & 3.01 & 3.72 & 3,36 \\
\hline W & 3,77 & 2.15 & 4.67 & 4,15 & $3.4<$ & 4,07 & 1,56 & 5,11 & $\angle, 04$ & 1,11 & 5.52 & 4.69 & $4,1 E$ \\
\hline$\overline{H O}$ & 4,67 & 3.06 & 2,4 & 4,02 & 3,16 & 4,03 & 1,56 & 5,12 & 3,53 & 1,31 & 3.32 & 3.67 & $4,<5$ \\
\hline$f_{i j}$ & 5 & $-1,09]$ & 4,12 & 5,06 & 5.15 & 4,71 & $5, A 5$ & 1,17 & 5,61 & 1, 1,6 & 1.0.11 & $4.5 C$ & 4,92 \\
\hline $1 \%$ & 5,1 & 3.6 & 5.12 & 5,11 & 3.52 & 1.97 & 1.25 & 3,59 & 3,03 & 1,59 & 3.47 & 5.75 & 4,15 \\
\hline
\end{tabular}

Sample of the study - The sample of our analysis consists of 2,678 firms located in 13 countries in the world studied throughout the Cranet research.

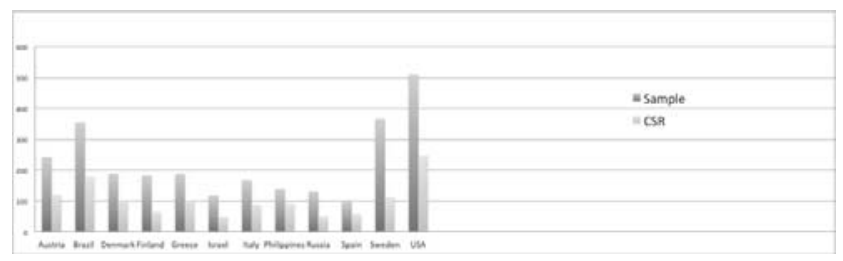

Figure 1 Presence of CSR statement in sample

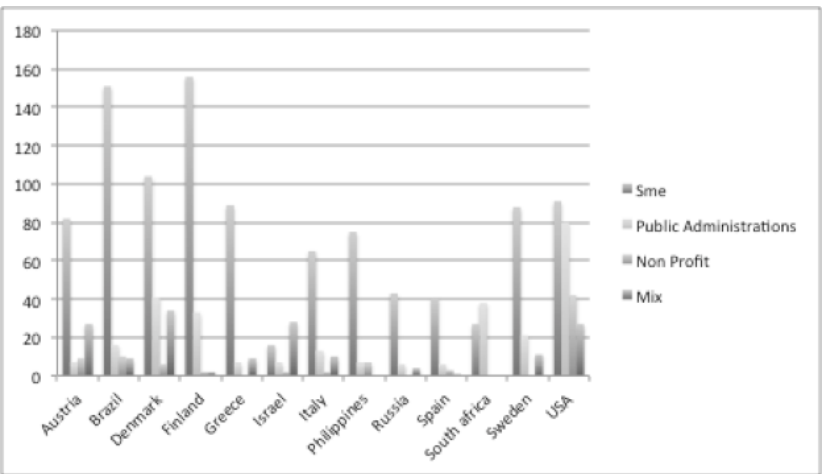

Figure 2 Presence of CRS statement in organizations

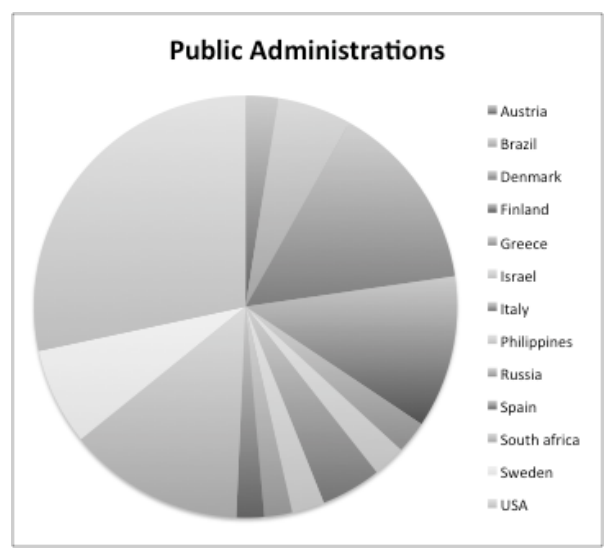

Figure 3 CRS statement in Public Administrations

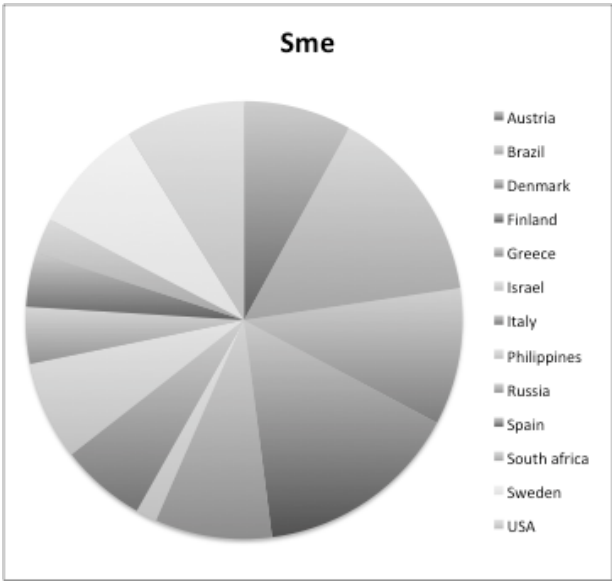

Figure 4 CRS statement in SME

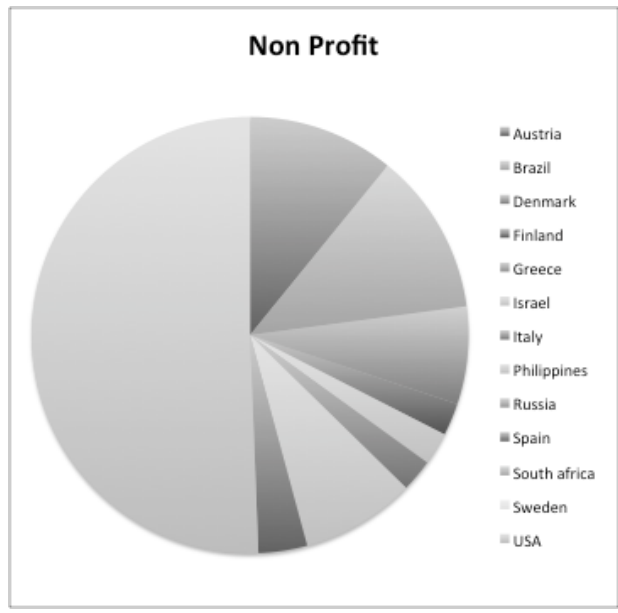

Figure 5 CRS statement in non-Profit Organizations 


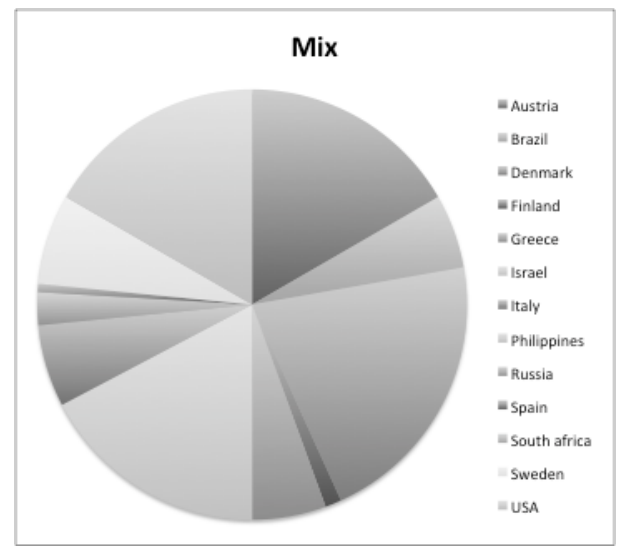

Figure 6 CRS statement in Mix Organizations

Our model is based on the following regression, considering as regressors the advanced Hofstede's cultural dimensions:

\section{$\mathrm{S}=\Upsilon 1 \mathrm{PDI}+\Upsilon 2 \mathrm{IDV}+\Upsilon 3 \mathrm{MAS}+\Upsilon 4 \mathrm{UAI}+\Upsilon 5 \mathrm{IND}+$ Y6PRG + e}

$\theta 1=$ coefficient of the PDI, i.e. effect on SM of a change of PDI, holding IDV; MAS; UAI;IND and PRG constant $\theta 2=$ coefficient of the IDV, i.e. effect on SM of a change of IDV, holding PDI; MAS; UAI;IND and PRG constant $\theta 3=$ coefficient of the MAS, i.e. effect on SM of a change of MAS, holding PDI;IDV; UAI;IND and PRG constant $\theta 4=$ coefficient of the UAI, i.e. effect on SM of a change of UAI, holding PDI;IDV; MAS;IND and PRG constant $\theta 5=$ coefficient of the IND, i.e. effect on SM of a change of IND, holding PDI, IDV; MAS; UAI; and PRG constant $\theta 6=$ coefficient of the PRG, i.e. effect on SM of a change of PRG, holding PDI, IDV; MAS; UAI and IND constant $\mathrm{e}=$ errors due to omitted variables

and Globe's cultural dimensions:

$\mathrm{S}=\theta 1 \mathrm{PDI}+\theta 2 \mathrm{IC}+\theta 3 \mathrm{ASS}+\theta 4 \mathrm{UA}+\theta 5 \mathrm{INC}+\theta 6 \mathrm{FO}++\theta$ $7 \mathrm{GE}+\theta 8 \mathrm{HO}+\theta 9 \mathrm{PO}+\mathrm{e}$

$\theta 1=$ coefficient of the PDI, i.e. effect on $\mathrm{S}$ of a change of PDI, holding IC, ASS, UA, INC, FO, GE, HO AND PO constant

$\theta 2=$ coefficient of the $\mathrm{IC}$, i.e. effect on $\mathrm{S}$ of a change of IC, holding PDI, ASS, UA, INC, FO, GE, HO AND PO constant

$\theta 3=$ coefficient of the ASS, i.e. effect on $\mathrm{S}$ of a change of ASS, holding PDI, IC, UA, INC, FO, GE, HO AND PO constant

$\theta 4=$ coefficient of the UA, i.e. effect on $\mathrm{S}$ of a change of UA, holding PDI, ASS, IC, INC, FO, GE, HO AND PO constant $\theta 5=$ coefficient of the INC, i.e. effect on $\mathrm{S}$ of a change of INC, holding PDI, ASS, IC, PD, FO, GE, HO AND PO constant

$\theta 6=$ coefficient of the FO, i.e. effect on $\mathrm{S}$ of a change of FO, holding PDI, ASS, IC, PD, INC, GE, HO AND PO constant

$\theta 7=$ coefficient of the GE, i.e. effect on $S$ of a change of GE, holding PDI, ASS, IC, PD, INC, FO, HO AND PO constant

$\theta 8=$ coefficient of the $\mathrm{HO}$, i.e. effect on $\mathrm{S}$ of a change of HO, holding PDI, ASS, IC, PD, INC, FO, GE AND PO constant

$\theta 9=$ coefficient of the PO, i.e. effect on $\mathrm{S}$ of a change of PO, holding PDI, ASS, IC, PD, INC, FO, GE AND HO constant

$\mathrm{e}=$ errors due to omitted variables

The Ordinary Least Squares Estimator minimizes the average squared difference between the actual value and the predicted value based on the estimated line.

Existing quantitative databases has been used as data sources and has been previously evaluated.

\section{Data Analysis And Results}

In the analysis of our analysis we have used software SPSS. In Table n.3 it's possible to see the results of Hofstede's correlation with CSR statement presence and of and Globe's correlation with CSR presence.

\begin{tabular}{|c|c|c|c|c|c|c|c|}
\hline Source & SS & $d f$ & \multicolumn{2}{|c|}{ MS } & & \multirow{2}{*}{$\begin{array}{l}\text { Number of obs } \\
\text { F( 6, 2671) } \\
\text { Prob > F }\end{array}$} & \multirow{2}{*}{$\begin{array}{l}=2678 \\
=\quad 6.63 \\
=0.0000\end{array}$} \\
\hline Model & 9.83159808 & 6 & \multirow{2}{*}{\multicolumn{2}{|c|}{1.63859968}} & & & \\
\hline Residual & 659.654959 & 2671 & & & & $\begin{array}{l}\text { R-squared } \\
\text { Adj R-squared }\end{array}$ & $=0.0147$ \\
\hline Total & 669.486557 & 2677 & .250 & 88367 & & Root MSE & $\begin{array}{l}=0.0125 \\
=.49696\end{array}$ \\
\hline A & Coef. & Std. & Err. & $\mathrm{t}$ & $P>|t|$ & [95\% Conf. & Interval] \\
\hline PDI & .0041636 & .0012 & 463 & 3.34 & 0.001 & .0017199 & .0066074 \\
\hline IDV & .0034113 & .001 & 591 & 2.34 & 0.019 & .0005501 & .0062724 \\
\hline MAS & .0036833 & .00 & 923 & 3.99 & 0.000 & .0018734 & .0054932 \\
\hline UAI & .0009357 & .000 & 108 & 1.83 & 0.067 & -.000066 & .0019374 \\
\hline PRA & .0027969 & .0017 & 736 & 1.58 & 0.115 & -.0006808 & .0062747 \\
\hline IND & -.0022121 & .0005 & 225 & -2.40 & 0.017 & -.004021 & -.0004033 \\
\hline _cons & -.1526202 & .2315 & 997 & -0.66 & 0.510 & -.606753 & .3015126 \\
\hline
\end{tabular}

\begin{tabular}{|c|c|}
\hline & Pearson Correlation \\
\hline Power_distance & $+^{* * *}$ \\
\hline Individualism vs Collectivism & $+^{* *}$ \\
\hline Masculinity vs Femininity & $+^{* * *}$ \\
\hline Uncertainty Avoidance & non relevant correlation \\
\hline Pragmatism & non relevant correlation \\
\hline Indulgence & \\
\hline
\end{tabular}


Table 4 Correlation between CSR statement and House's model regress A ASS IC INC FO GE PD HO PO UA

\begin{tabular}{|c|c|c|c|c|c|}
\hline Source & ss & $d f$ & MS & Number of obs $=$ & 2678 \\
\hline Model & 12.1743276 & 9 & 1.35270307 & Prob $>\mathrm{F}$ & 0.0000 \\
\hline Residual & 657.312229 & 2668 & .246368902 & R-squared & 0.0182 \\
\hline Total & 669.486557 & 2677 & .250088367 & Root MSE & . 49636 \\
\hline
\end{tabular}

\begin{tabular}{r|rlrrrr}
\hline $\mathrm{A}$ & Coef. & Std. Err. & $\mathrm{t}$ & $\mathrm{P}>|\mathrm{t}|$ & \multicolumn{1}{l}{ [95\% Conf. Interval] } \\
\hline ASS & -.1451744 & .0762234 & -1.90 & 0.057 & -.2946373 & .0042885 \\
IC & -.2150551 & .0713356 & -3.01 & 0.003 & -.3549337 & -.0751765 \\
INC & .0303614 & .0198134 & 1.53 & 0.126 & -.0084898 & .0692126 \\
FO & .1039817 & .0871023 & 1.19 & 0.233 & -.0668132 & .2747766 \\
GE & .0033911 & .0491831 & 0.07 & 0.945 & -.0930499 & .099832 \\
PD & .0383483 & .0189814 & 2.02 & 0.043 & .0011286 & .0755681 \\
HO & .0542024 & .0448823 & 1.21 & 0.227 & -.0338052 & .1422099 \\
PO & -.0167263 & .0252801 & -0.66 & 0.508 & -.0662969 & .0328443 \\
UA & -.0201742 & .0485262 & -0.42 & 0.678 & -.115327 & .0749785 \\
Cons & 1.260915 & .4597584 & 2.74 & 0.006 & .3593965 & 2.162434
\end{tabular}

\begin{tabular}{|l|r|}
\hline & Pearson Correlation \\
\hline Assertivism & non relevant correlation \\
\hline Instit Collectivism & $-^{* * *}$ \\
\hline InGroup Collectivism & non relevant correlation \\
\hline Future Orientation & non relevant correlation \\
\hline Gender Egalitarianism & non relevant correlation \\
\hline Power Distance & \\
\hline Humane Orientation & non relevant correlation \\
\hline Performance Orientation & non relevant correlation \\
\hline Uncertainty Avoidance & non relevant correlation \\
\hline
\end{tabular}

Thus, we can affirm that regressors are an effective cause of the movements of the dependent variable, that is, the Hofstede's cultural dimensions (PDI, IDV, MAS, IND) influence sustainability (Hypothesis 1). Also Globe's variables (IC and PDI) influence sustainability (Hypothesis 1). Obviously we have different results. For Hofstede's dimensions there is a positive correlation for Power Distance, Individualism and Masculinity, while there is a negative correlation for Indulgence. For Globe's dimensions there is a positive relation for Power Distance while there is a negative relation for Institutional Collectivism. (Hypothesis 2).
There is no doubt about the importance of CSR for the implementation of HRM. The presence of CSR in organization implement the attractiveness of a firm because improve candidate perceptions (Greening \& Turban, 2000). A good reputation socially implies that an organization's behavior is sustainable both with employees both with the external stakeholders (Redington, 2005). It means respect for cultural and developmental differences and sensitivity to imposing values, ideas and beliefs (Nancy, 2004). Competitive organizations must now learn to develop the ability to attract individuals who can stimulate innovation behavior or who know how to acquire the techniques and principles of sustainability. Consequently, the knowledge-oriented organizations should always select subjects that quickly adapted to change. Sometimes to work in a sustainable firm is more important than the salary (Murray, 2008). People prefer to work in firms where there is an organizational well-being, that is "the set of cultural elements, processes, and organizational practices that animate the dynamics of coexistence in work context, promoting, maintaining and improving the quality of life" (Avallone, 2005). A sustainable organization promotes an ethical culture, a respectable and integrated behavior, an empowerment that use collaborative networks, a political of equity, an open and interactive dialogue with stakeholders, a corporate transparency. This improves the creation and acquisition of knowledge, making it less tacit, but available and pervasive, enabling organizations to experiment a sort of virtualization of the chain of value, transferring some phases of the physical chain to a more cognitive dimension, trying to contemporarily manage the two chains of the value in a separate and permanent manner. From this point of view, the learning that feeds the cognitive die is constituted by relationships that give holistic nature to the meanings with which experiences are understood and organized in the life of everyone. Then, if CSR increase knowledge sharing and MAS, IND, PDI and UAI have a correlation with sustainability it is easy to perceive that if managers encourage these dimensions, it is possible for individual, groups and organization to develop knowledge management.

\section{References}

[1] Carroll, B. (1999). Corporate Social Responsibility. Evolution of a Definitional Construct. Business Society, 38: 268-274

\section{Conclusions}


[2] Ehnert, I. (2009). Sustainable Human Resource Management: A conceptual and exploratoy analysis from a paradox perspective. Berlin.

[3] McWilliams, A., Siegel, D. and Wright, P.M. (2006) 'Corporate social responsibility: strategic implications', Journal of Management Studies 43(1): 1-18.

[4] WCED (World Commission on Environment and Development), 1987. Our Common Future. Oxford University Press, Oxford.

[5] Savitz, W. and Weber, K. (2006). The triple bottom line: how today's best-run companies are achieving economic, social and environmental success- and how you can too. John Wiley \& Sons, San Fransisco.

[6] Elkington, J. (1997). Cannibals with Forks: The Triple Bottom Line of 21st Century Business. Capstone, Oxford [7] Gladwin, T.N., Kennelly, J.J. and Krause, T.-S. (1995), "Shifting paradigms for sustainable development: implications for management theory and research", Academy of Management Review, Vol. 20 No. 4, pp. 874907.

[8] Gravili G., Miglietta P., De Leo F., (2016), Social Media and Environmental Sustainability: An Overview of European Countries, in International Journal of Business and Management, Vol. 11, No. 6; pag. 1-10, Published by Canadian Center of Science and Education ISSN 18333850 E-ISSN 1833-8119 1.

[9] Hofstede, G.H. (2001). Culture's consequences: Comparing values, behaviors, institutions, and organizations across nations (2 edition). Beverly Hills, CA: Sage Pubblications. [10] House, R. J., Hanges, P. J., Javidan, M., Dorfman, P. W., \& Gupta, V. (Eds.). (2004). Culture, leadership, and organizations: The GLOBE study of 62 societies. Sage publications.

[11] Jones-Christensen, L., Pierce, E., Hartman, L. P., Hoffman, W. M. and Carrier, J. (2007), Ethics, CSR, and sustainability education in the Financial Times top 50 global business schools: Baseline data and future research directions. Journal of Business Ethics, 73(4): 347-368.

[12] Katz, J.P., Swanson, D.L. and Nelson, L.K. (2001). Culture-based expectations of corporate citizenship: propositional framework and comparison of four cultures. International Journal of Organizational Analysis, 9, 2, 149-172.

[13] Park, H., Russell, C. and Lee, J. (2007). National culture and environmental sustainability: A cross-

national analysis. Journal of Economics and Finance, 31, $1,104-121$.

[14] Rosen, D., Stefanone, M. A. and Lackaff, D. (2010). Online and offline social networks: Investigating culturally-specific behavior and satisfaction. In Proceedings of the 43rd Hawai $i$ International Conference on System Sciences. New Brunswick: Institute of Electrical and Electronics Engineers, Inc. (IEEE).
Ginevra Gravili, was born in Lecce on 07 October 1969. She graduated in Economic Studies in 1992, and she achieved PHD in Management and Organization in 1996. Since 2002, she is professor of Organization Theory at University of Salento, Department of Economics and Management, Lecce, Italy. She has written numerous books and articles on sme's, knowledge sharing, social recruitment, sustainability, HRM of public administration, ICT, social media and organizations. 